NOTAS DE PESQUISA 


\section{O PORTO DO DESTERRO NAS RELAÇÕES BRASIL-ESTADOS UNIDOS}

(1831-1874)

Walter F. Piazza

\section{Introdução}

As relações Brasil-Estados Unidos podem, inicialmente, ser subdivididas em duas fases distintas, a saber: a pré-independência e a pós-independência do Brasil.

Os aspectos políticos destas relações têm merecido maior atenção do que qualquer outro aspecto.

Daí por que, neste estudo, nos cingimos ao papel do Consulado norte-americano no Desterro e as funções que ali exerceu.

\section{As rotas do comércio norte-americano, no século XIX}

A bibliografia compulsada nos fala da importância da rota do Cabo Horn para as ligações das costas leste-oeste da grande nação do norte no século XIX, notadamente no período posterior a 1848. Entretanto, já em 1831, com a instalação do Consulado norte-americano no Desterro (atual Florianópolis, Ilha de Santa Catarina), como se verá, era importante esta rota meridional.

Morison e Commager referem que "[...] depois de dois séculos de colonização, a fronteira povoada dos Estados Unidos, só chegava, em 1830, à metade do continente". ${ }^{1}$

E continuam:

Quando Lewis e Clarke (1806) deram notícia de uma reserva intata de animais que poderiam prover de peleteria no coração do cntinente, fundaram-se companhias comerciais com vistas a sua caça. ${ }^{2}$

Por outro lado, nessa época, para alcançar-se o longínquo oeste havia três possíveis caminhos:

[...] uma rota era pelas embarcações ao redor da América do Sul. Era uma rota demorada, pois, a viagem levava de cinco a sete meses. Outra rota era por barco até a cidade de Chagres, na costa leste do Panamá. O seu custo era de US\$380. Daí, por canoa, seguia-se para o interior pelo rio Chagres, até a cidade do Panamá, e daí de navio até San Francisco. O custo da passagem de navio era de US\$1.000. A terceira rota era terrestre. ${ }^{3}$ 
Deve-se aqui, pois, considerar que, de Nova York a San Francisco, o caminho marítimo do extremo sul da América (Cabo Horn) equivale a 13.130 milhas, enquanto que a segunda opção, equivalente, hoje, à rota do canal do Panamá, significava um percurso de 5.260 milhas.

Por outro lado é importante ressaltar-se a posição privilegiada da Ilha de Santa Catarina nos tempos da navegação à vela, como ponto de arribada de navios, indos ou vindos do e para o Pacífico.

Testemunho disto está nestas linhas:

Os navios balieiros no seu regresso dos mares do Sul costumão arribar a este Porto a refrescar, a refazer mantimentos para a continuação da viagem. ${ }^{4}$

\section{O Consulado norte-americano no Desterro}

Desde que se teve notícia da existência de um Consulado norte-americano na então cidade do Desterro, capital da Província (hoje Estado) de Santa Catarina, interessou-nos conhecer a que se devia tal importante situação no relacionamento entre as duas maiores nações do continente americano.

Das notícias de jornais desterrenses, partiu-se para pesquisas que esclarecessem o assunto.

Encontrou-se a resposta preliminar - a existência de documentação nos arquivos norte-americanos - em trabalho de eminente pesquisador ianque sobre as relações consulares norte-americanas com o Brasil. ${ }^{5}$

O segundo passo seria dado, em seguida, numa visita nossa a Washington, para participar de reunião científica, em 1973.

Coletaram-se os documentos na íntegra.

Mas, na cidade do Desterro, onde se localizava este Consulado?

Eis a resposta.

Em 1867, o Consulado dos Estados Unidos, na cidade do Desterro, funcionava no Largo do Palácio (hoje Praça 15 de Novembro), n. $^{0} 5$, tendo no andar térreo uma casa comercial, onde se vendia farinha de trigo, recebida daquele país. ${ }^{6}$

Era, pois, uma casa de sobrado, pelo menos, onde se hasteava o pavilhão norte-americano, em ponto central da capital catarinense.

\section{Os papéis do Consulado}

O material respeitante ao Consulado, foi microfilmado no National Archives de Washington, D.C., USA, e é deveras importante para a compreensão de alguns aspectos da posição do Brasil com aquela nação do hemisfério norte. ${ }^{7}$

Tal documentação, contida em dois rolos de microfilme, abrange, basicamente, a correspondência dos cônsules norte-americanos na então cidade do Desterro (hoje Flo- 
rianópolis), dirigida aos Secretários de Estado do Governo dos Estados Unidos, que se sucederam entre 1832 e 1874.

A correspondência evidencia o papel econômico dos consulados: a sua vigilância sobre as embarcações de bandeira norte-americana, que entravam no Porto do Desterro. Assim, periodicamente, de seis em seis meses, eram remetidos a Washington mapas da entrada e movimentação das embarcações, contendo o seu nome, do seu "mestre", ou comandante, a sua tonelagem, o número de seus tripulantes, a descrição sumária da sua carga, os seus pontos de partida e de destino, e acompanhava-os outro mapa das taxas cobradas desses navios pelo Consulado.

À margem destes mapas eram escritas observações sobre algum incidente ou acidente ocorrido com os navios ou os seus tripulantes, e quase sempre neles se obtinha a correlação "mil réis" com o dólar, na data do fechamento do mapa.

Eventualmente os cônsules davam uma informação sobre a situação política do Brasil.

É o caso da carta do Cônsul Lemuel Wells ao Secretário de Estado John Forsyth, datada de 11 de junho de 1836, onde se refere à Guerra Civil na Província do Rio Grande ("Guerra dos Farrapos") e acentua que "a Provincia de Sta. Catarina está quieta e não há distúrbios" e sobre este mesmo evento, o mesmo remetente ao mesmo destinatário, em $1 .^{\circ}$ de setembro de 1837 , esclarece que "presentemente em negócios políticos nesta Provincia (Sta. Catarina) nada há e que continua a guerra civil no Rio Grande e que a opinião pública naquela provincia é favorável à revolução".

Já, em 2 de abril de 1839, há uma revelação sobre o movimento "farroupilha" em Santa Catarina:

On the 15th last month the Inhabitants of the western district of this Province (call Lages) revolted against the Imperial Government and joined the revolutionary party of Rio Grande and the Inhabitants are principally Heardsman.

The Brazilian Minister of War arrived here a few days since on his way to Rio Grande by sea with about Troops. I am informed that the Government forces amt. to 5000 Men and the revolutionary Army to about same number, well armed, and good soldiers.

E o depoimento da carta de $1 .^{\circ}$ de janeiro de 1840 , do mesmo remetente ao mesmo destinatário, se torna expressivo:

Since my last letter $\left(n^{\circ}{ }^{\circ}\right.$ ) the Imperial Troops (about 2000 in number) have succeded in retaking the Tourn of Laguna in this Province and a countre-revolution has taken place in the western district of this Province (Lages) no favorise of the Imperial Command. On the 12 th of December last the Imperial General Cunha with 2 to 1500 Men entered Lages from the Province of St. Paul and marched to the frontier of Rio Grande.

E, na mesma carta, após descrever outras operações, conclui:

The District of Lages is again occupied by the Revolutionists and part of then Troops have appeared in the vicinity of Laguna.

E, cessados os movimentos farroupilhas em Santa Catarina, na carta de $1 .^{\circ}$ de outubro de 1841, declara: "In political and commercial affaires in this Province nothing of note to communicate". 
Mais tarde, em dez páginas manuscritas, o Cônsul Wells sumariza para o Secretário de Estado James Buchanan, a visita de D. Pedro II e de D. Teresa Cristina à Província de Sta. Catarina. É a carta n. ${ }^{\circ}$ 52, datada de 12 de novembro de 1845.

Posteriormente, a 10 de agosto de 1846 , do mesmo remetente ao mesmo destinatário, trata-se da celebração de um tratado de comércio entre o Brasil e os Estados Unidos.

E, entremeando os papéis do Consulado, encontra-se uma raridade bibliográfica: “Apontamentos sobre a cultura do chá, colegidos de varias memorias, e offerecidos aos agricultores catharinenses", de autoria do Brigadeiro José Joaquim Machado de Oliveira, que foi Presidente da Província de Sta. Catarina e teve destaque na vida militar, política e cultural do Império Brasileiro. O referido trabalho foi editado no Desterro, pela Tipografia Provincial, em 1837, contendo 10 páginas.

Em 1849, pela carta ${ }^{\circ}{ }^{\circ} 2$, de 15 de junho de 1849 , fica-se sabendo que há novo Cônsul. É esta a comunicação do novo titular do Consulado, Thomas C. Mac Dowell, ao Secretário de Estado, John M. Clayton, de sua chegada a St. ${ }^{\text {a }}$ Catarina e posse, bem como contém pormenores sobre sua apresentação ao Presidente da Província e os entendimentos com Lemuel Wells, seu antecessor no Consulado.

O Consulado, depois, passa para outras mãos. Os "Consular return statement" e os "Consular statement of fees" são assinados, inicialmente, por Robert S. Cathcart, que o passa, em seguida, a A. M. Ropz.

Este, em carta $\left(\mathrm{n}^{\circ}\right.$ 2) datada de 30 de janeiro de 1851, dirigida ao Secretário de Estado, Daniel Webster, junta o inventário dos bens do Consulado, dizendo que os recebeu de Robert S. Cathcart e afirmando ter este os recebido de Wells.

Em outra correspondência, de n. ${ }^{\circ} 4$, datada de 8 de março de 1851 , para o mesmo destinatário, afirma que Wells possuía dinheiros governamentais e em "post-scriptum" esclarece que Wells estava ausente, no Rio de Janeiro, à época de sua chegada ao Desterro, em 27 de janeiro daquele ano.

Daí por diante, os papéis consulares se limitam à movimentação de embarcações norte-americanas, através dos "Consular return" e à cobrança das taxas consulares, retratadas nos "Consular statement of fees" e, assim, até outubro de 1874.

São, pois, estes os documentos mais importantes, onde se assinala o movimento de embarcações baleeiras norte-americanas no porto do Desterro, tornando-o base para os seus suprimentos.

\section{Os Cônsules}

Os documentos manuseados apontam como Cônsules norte-americanos na cidade do Desterro (alguns escrevem "Ilha de Santa Catarina") os seguintes cidadãos, cujos períodos de permanência na função são, após seus nomes, colocados entre parênteses.

Ei-los:

O primeiro Cônsul norte-americano que se encontra na então cidade do Desterro é Lemuel Wells (1831-1849). ${ }^{8}$ 
A sua atividade inicia-se a 17 de outubro de 1831 e encerra-se a 4 de junho de 1849 , quando entrega o Consulado a Thomas C. Mc Dowell.

$\mathrm{Na}$ ausência de Wells - de 13 de maio de 1835 a 6 de novembro de 1835 - esteve respondendo pelo Consulado, como "Acting Consul", John C. Pedrick (1835). ${ }^{9}$

É importante assinalar, aqui, que ambos, Wells e Pedrick, formaram uma sociedade comercial na cidade do Desterro com José Gonçalves dos Santos Silva ${ }^{10}$, para exploração de uma porção do vale do rio Tijucas e, ali, instalaram uma serraria, dando ao local a denominação de "Serras" e tendo como trabalhadores cidadãos norte-americanos. ${ }^{11}$

Em outra oportunidade foi Wells substituído por William Ricken (de 20.05.1840 a 22.12.1840).

Thomas C. Mc Dowell chega à cidade do Desterro a 2 de junho de 1849 e toma posse do Consulado no dia 4 daquele mês e ano.

A sua permanência à testa do Consulado dá-se por período indeterminado, porquanto passou a gestão dos negócios da sua pátria ao concidadão, residente em $\mathrm{St}^{\mathrm{a}}$ Catarina, Robert S. Cathcart que, a 30 de janeiro de 1851, transmitiu o cargo ao novo Consul, A. M. Ropz.

A administração consular de Ropz se estende até 23 de março de 1859, quando a assume, novamente, Robert S. Cathcart.

Este gere os assuntos consulares até 10 de agosto de 1861, tendo, entretanto, posteriormente, em carta ao Secretário de Estado, William H. Steward, alegado que resignara ao cargo de Cônsul em razão de sua "avançada idade" e da sua "residencia em uma grande distancia da cidade".

Coube substituir a Cathcart o Cônsul Benjamin Lindsay, que tomou posse, como se viu acima, a 10 de agosto de 1861.

Lindsay teve que se ausentar para os Estados Unidos, onde, de Boston e de New Bedford, escreveu ao Secretário de Estado.

Na sua ausência respondeu pelo Consulado o Vice-Cônsul William H. Willington.

Dá-se a 2 de fevereiro de 1874 a resignação de Lindsay como Cônsul e a 19 de junho daquele ano de 1874 é abolido o Consulado dos Estados Unidos da América na cidade do Desterro.

\section{O movimento marítimo norte-americano no porto do Desterro}

Com a documentação que se possui, o estudo do movimento marítimo norte-americano no porto do Desterro pode ser desdobrado, ano por ano, de 1831 a 1874 - data do fechamento do consulado ianque no porto do Desterro - através dos seguintes elementos: nome das embarcações, sua tonelagem, número de seus tripulantes, quer norte-americanos, quer estrangeiros, a carga transportada, e, naquele porto, a que foi descarregada, os seus portos de origem e de destino, os seus "mestres" ou comandantes e os seus proprietários. 
Comose vê, há um largo material a ser considerado.

Entretanto, antes de nos ater aos dados quantitativos, vale respingar algumas informações colhidas em outras fontes.

Sobre a freqüência de barcos norte-americanos no porto do Desterro, assim se reporta Southey:

Mui productiva havia sido em Santa Catharina a pesca da baleia, declinára porem desde que os baleeiros americanos frequentavam as ilhas de Falkland, sendo na verdade tão pertinaz e destruidora a guerra que se faz a estes animaes collossaes, porem inofensivos, que já raras vezes ou nunca se encontram tão grandes como outrora, sendo provavel que dentro em poucas gerações se extinguisse a raça, se o uso geral das luzes de gaz não tivesse vindo diminuir a demanda de azeite de peixes. ${ }^{12}$

E sobre a permanência dos norte-americanos ou a sua passagem, existem vários informes na imprensa desterrense.

Veja-se este informe, colhido sob a rubrica "Registro do porto":

Entrada dia 30: da pesca com 16 mezes, barca americana 'Benjamin Franklin', 167 toneladas, c. 350 barrís de azeite ao mestre. ${ }^{13}$

Ou, ainda, este:

Entrada dia 12. Patacho americano 'Panamá', 158 tons. eq. 26. Com azeite ao mestre. ${ }^{14}$

Leia-se, sempre, que tais dados são básicos para a compreensão da problemática da ocorrência do porto do Desterro nesta rota náutica: era ponto de apoio.

Ainda, anote-se:

Entrada a 24 (de maio):

- Pesca, com 3 mezes de viagem, hiate americano "Seaward", de 116 toneladas, mestre Samuel W. Roija, equipagem 17 , carga azeite, consignada ao mestre. ${ }^{15}$

Ou, então, este outro:

Boston, com destino a California, arribado a este porto por falta d'agua e lenha, com 59 dias de viagem, hiate americano "Caleb Curtis" de 90 tons. m. Henry Bangs, equip. 7, carga lastro e comestíveis. ${ }^{16}$

O movimento dos baleeiros norte-americanos era de tal importância que, de quando em vez, deixavam-se por aqui ficar:

Vende-se uma bonita e boa baleeira de construção americana, tendo 36 palmos de comprimento e $71 / 2$ de boca, com todos os seus preparos, quem pretender comprar dirija-se ao abaixo assignado. Desterro, 3 de maio de 1867. João de Souza Freitas. ${ }^{17}$

Ou, então, esta notícia:

De New York com destino a Valparaiso, arribada a este porto por falta d'água e viveres, com 60 dias de viagem, escuna a vapor norte-americana Donald, de 132 tons., m. C. Danreiter, equipagem 7 pessoas. Em lastro carvão e cimento. ${ }^{18}$ 
Este informe mostra a necessidade de apoio no porto do Desterro: água e víveres.

Vistos estes aspectos, onde se ressalta a importância do porto do Desterro nas épocas de navegação à vela $\mathrm{e}$, também, no princípio da navegação a vapor, mostraremos os elementos constantes dos documentos norte-americanos, no tocante ao número de navios entrados no porto do Desterro, a sua tonelagem e o número dos seus tripulantes.

Estes são os dados:

\begin{tabular}{|c|c|c|c|c|}
\hline \multirow{2}{*}{ Períodos } & \multirow{2}{*}{$N^{\mathbf{O}}{ }^{\text {de Embarcações }}$} & \multirow{2}{*}{ Tonelagem } & \multicolumn{2}{|c|}{ N. ${ }^{\mathbf{o}}$ de Marinheiros } \\
\hline & & & Norte-americanos & Estrangeiros \\
\hline 1831 & 5 & 881,00 & 47 & \\
\hline 1832 & 19 & $8.842,70$ & 301 & \\
\hline 1833 & 24 & $4.700,03$ & 291 & 5 \\
\hline 1834 & 22 & $4.576,89$ & 297 & 37 \\
\hline 1835 & 20 & $1.455,82$ & 523 & 45 \\
\hline 1836 & 19 & $4.579,56$ & 286 & 75 \\
\hline 1837 & 23 & $5.943,37$ & 379 & 85 \\
\hline 1838 & 21 & $6.268,30$ & 395 & 129 \\
\hline 1839 & 20 & $4.404,88$ & 289 & 63 \\
\hline 1840 & 23 & $5.573,57$ & 419 & 38 \\
\hline 1841 & 32 & $8.731,73$ & 580 & 127 \\
\hline 1842 & 14 & $3.541,29$ & 209 & 65 \\
\hline 1843 & 20 & $5.116,95$ & 287 & 65 \\
\hline 1844 & 16 & $4.110,34$ & 201 & 86 \\
\hline 1845 & 24 & 5.630 .63 & 355 & 90 \\
\hline 1846 & 23 & $6.337,87$ & 387 & 96 \\
\hline 1847 & 24 & $6.339,85$ & 388 & 119 \\
\hline 1848 & 21 & $4.938,83$ & 320 & 107 \\
\hline 1849 & 24 & $6.988,31$ & 353 & 11 \\
\hline 1860 & 5 & $2.159,03$ & 83 & 26 \\
\hline 1861 & 2 & 829,52 & & \\
\hline 1866 & 14 & $4.552,00$ & & \\
\hline 1871 & 2 & $1.507,00$ & & \\
\hline
\end{tabular}

FONTE: NATIONAL ARCHIVES, Washington, DC. Consular return statement. US Consul St. Catharina Island.

A compilação dos dados anteriores, pelo Consulado, tem início a 17 de outubro de 1831, de forma que, nesse ano, apresenta um movimento bastante insignificante.

No tocante ao número de marinheiros, vai-se ter somente a divisão entre norteamericanos e estrangeiros, a partir de $10^{\circ}$ de julho de 1833.

Outra ocorrência é a falta de anotação, pelo Consulado, no período de $10^{\circ}$ de janeiro a 30 de junho de 1835, da tonelagem das embarcações arribadas no porto do Desterro.

São também incompletos os dados de 1849 (1. ${ }^{\circ}$ de janeiro a 30 de junho), 1860 (1..$^{\circ}$ de julho a 30 de setembro), 1861 ( $1 .^{\circ}$ de janeiro a 31 de março), 1866 ( 31 de março a 30 de setembro) e 1871 ( 30 de junho a 30 de setembro). 
A análise dos dados acima, onde se sintetiza a operacionalidade do porto do Desterro por embarcações de bandeira norte-americana, nos mostra a falta de dados com o período da Guerra Civil (1860-1865) e após esse período a falta de continuidade e a inexistência de dados.

Os dados após 1866 indicam o decréscimo de barcos norte-americanos no porto do Desterro, o que, evidentemente, levaria ao fechamento do Consulado.

Face ao exposto, algumas conclusões se impõem:

1. A pesca da baleia e a transformação do seu azeite em elemento de iluminação propiciou grande tráfego marítimo nos "mares do Sul", cabendo ao porto do Desterro importante papel de apoio.

2. No momento do desuso do azeite de baleia para iluminação e o surgimento do querosene como combustível para iluminação (quer querosene produzido a partir do carvão de pedra (1850/51), quer a partir do petróleo (1859), cessa a atividade da caça à baleia, o que ocorre após a Guerra Civil.

3. Com esta cessação diminui o uso da "rota do Cabo Horn" ou a freqüência aos "mares do sul", deixando o porto do Desterro de ter função primacial nesse tráfego marítimo, o que coincide com o final da Guerra Civil e a desorganização da marinha mercante daquele país.

4. Tais condições implicam, evidentemente, no fechamento do Consulado norteamericano no Desterro (1874).

Centro de Ciências Humanas

Universidade Federal de Santa Catarina

Florianópolis - Brasil

\section{NOTAS}

${ }^{1}$ Historia de los Estados Unidos de Norteamérica (México: Fondo de Cultura Económica, 1951), v.I, p.554.

2 Id., ibid., p.555.

${ }^{3}$ Rebekah Liebman \& Gertrude A. Young, Growth of America (New York: Prentice-Hal Inc., 1966), p.257.

${ }^{4}$ Arquivo Nacional do Brasil, IJJ 9.438, Seção dos Ministérios. Ofício do Presidente da Província de Santa Catarina, Francisco d'Albuquerque Mello, ao Ministro Pedro d'Araujo Lima, a 15 de Janeiro de 1828.

5 John P. Harrison, "The archives of United States diplomatic and consular posts in Latin America”. Hispanic A merican Historical Review, 33:163-83, 1953.

${ }^{6} O$ Despertador, jornal, Desterro, SC., n. ${ }^{\circ} 435$, ed. 19.03 .1867$, p.4, c.3. 
${ }^{7}$ A aquisição do material microfilmado fez-se com a interveniência do Dr. Clifford Evans, da Divisão de Antropologia do Smithsonian Institution, que nos acompanhou na visita e nas gestões junto ao National Archives.

8 Lemuel Wells e não Samuel como está grafado no "Registro de Estrangeiros" (1840-1842), Rio de Janeiro, publicação do Arquivo Nacional, 1964, p.53: “parte a 29/07/1841” para Santa Catarina, e é qualificado como "Cônsul americano".

9 A movimentação de John C. Pedrick está assim anotada no Registro de Estrangeiros (1840-1842), Rio de Janeiro, Arquivo Nacional, 1964, p.113: a 15/04/1840 "parte para Santos", a 22/12/1840 "parte para o Rio Grande" e a 03/04/1841 "vem de Baltimore".

10 José Gonçalves dos Santos Silva era português. Filho do negociante Antonio Gonçalves da Silva e de D. Rosa Maria da Conceição Silva, nasceu na cidade do Porto, a 9 de abril de 1794. Fez os primeiros estudos no Colégio das Antas e depois passou a trabalhar no comércio. Ligou-se à Sociedade Secreta Sinhédrio, organizada em Lisboa para derrubar o absolutismo. Derrotada a conspiração fugiu para Londres e só retornando a Portugal em 1827. Passoutse para o Rio de Janeiro e, em 1829, chegou a St. ${ }^{\text {a }}$ Catarina. Teve projeção social, econômica e cultural. Autor de vários trabalhos de interesse à história catarinense.

11 Walter Piazza, Nova Trento (Florianópolis: Imprensa Oficial do Estado, 1950), p.19-20.

12 Lucas A. Boiteux, Notas para a história catarinense (Florianópolis: Liv. Moderna, 1912), p. 298.

13 A Argos da Provincia de Santa Catarina, jornal, Desterro, 31/03/1860, p.4.

140 Argos, 27/11/1860, p.4.

15 O Argos, n. ${ }^{\circ} 703,25 / 05 / 1861$, p.4.

16 O Argos, $\mathrm{n}^{\circ} 805,08 / 10 / 1861, \mathrm{p} .4$.

17 O Despertador, n. ${ }^{\circ} 456,04 / 06 / 1867$, p.4.

18 O Despertador, n. ${ }^{\circ} 657,15 / 05 / 1869$, p.4. 